\title{
Formulação de Iogurte Concentrado Enriquecido com Farinha de Semente de Uva: Atividade Antioxidante e Cinética de Fermentação
}

\section{Formulation of Concentrated Yoghurt Enriched With Grape Seed Flour: Antioxidant Activity and Fermentation Kinetics}

\author{
Rafael Fagnani*ab; Priscila Micheli da Silva Boniatti ${ }^{c}$ \\ aUnopar, Programa de Pós-Graduação Stricto Sensu em Ciência e Tecnologia de Leite e Derivados. PR, Brasil. \\ bUnopar, Programa de Pós-Graduação Stricto Sensu em Saúde e Produção Animal. PR, Brasil. \\ 'Unopar. PR, Brasil \\ *E-mail: rafael.fagnani@kroton.com.br
}

\begin{abstract}
Resumo
Os iogurtes concentrados enriquecidos com ingredientes funcionais vêm ocupando cada vez mais espaço no mercado. A farinha de semente de uva possui compostos fenólicos antioxidantes e está associada à prevenção de doenças degenerativas. O objetivo foi elaborar um iogurte concentrado enriquecido com farinha de semente de uva, avaliando a cinética de fermentação e as características físico-químicas e microbiológicas. Durante a fermentação, o pH e a velocidade de multiplicação das bactérias ácido láticas foram analisados. Após a produção, as análises abrangeram a atividade antioxidante, composição centesimal, colorimetria, viscosidade e o perfil de textura. O tempo de fermentação foi de $8 \mathrm{~h}$, alcançando $\mathrm{pH} 4,5$ e contagens de bactérias ácido láticas de $9 \log \mathrm{UFC} / \mathrm{mL}$. Após $24 \mathrm{~h}$, as contagens de coliformes totais, bolores e leveduras porcentagem proteica e lipídica atenderam aos parâmetros exigidos pela legislação brasileira para iogurtes parcialmente desnatados. A textura e a viscosidade mostraram boa firmeza do coágulo e ficaram dentro dos valores esperados para iogurtes concentrados. A coordenadas CIELAB apoiaram a percepção visual de uma coloração levemente lilás, denotando a presença de um subproduto da uva. Quando comparada a outros estudos, a capacidade antioxidante foi expressiva, superior aos iogurtes tradicionais e aos enriquecidos com frutas vermelhas com as palavras "antioxidante" no rótulo. Esses resultados indicam adequada formulação, com bons resultados físico-químicos e microbiológicos, podendo fornecer parâmetros para a sua exploração industrial.
\end{abstract}

Palavras-chave: Leite Fermentado. Bactérias Ácido Láticas. Textura. Colorimetria.Funcional.

\begin{abstract}
Concentrated yogurts enriched with functional ingredients possess high market potential for investment, owing to the rise in demand and increase in awareness regarding their health benefits. Grape seed flour has phenolic compounds which are antioxidant and have been associated with the degenerative diseases prevention. The objective of this study was to formulate a concentrated yogurt enriched with grape seed flour, evaluating the fermentation kinetics, physical-chemical and microbiological characteristics. During fermentation, the pH and the multiplication rate of the lactic acid bacteria were analyzed. After production, the antioxidant activity, chemical composition, colorimetry, viscosity and texture profile were analyzed. The fermentation time was 8 hours, reaching $p H 4.5$ and lactic acid bacteria counts of 9 log CFU/ $m L$. After $24 \mathrm{~h}$, the count of total coliforms, molds and yeasts, protein and lipid percentage complied with the Brazilian legislation for partially skimmed yoghurts. As expected, the texture and viscosity showed a strong coagulum and within the values for concentrated yogurts. The coordinates of the CIELAB system supported the visual perception of a light lilac color, denoting the presence of a grape by-product. When compared to other studies, the antioxidant capacity was expressive, superior to traditional yogurts and even those enriched with red fruits with "antioxidant" on the label. The enrichment of concentrated yoghurt with grape seed flour can be explored industrially, with satisfactory results of physicochemical, microbiological and antioxidant capacity.
\end{abstract}

Keywords: Fermented Milk. Lactic Acid Bacteria. Texture. Colorimetry. Functional.

\section{Introdução}

No Brasil e nos EUA o iogurte concentrado é denominado "iogurte grego" (greek yoghurt ou greek-style yoghurt) e sua comercialização é relativamente recente quando comparada aos países do oeste do mediterrâneo, Turquia, Grécia, Índia e Dinamarca, onde é conhecido como Labneh, Torba, Stragisto, Chakka e Ymer, respectivamente (ARYANA; OLSON, 2017).

Os iogurtes concentrados foram introduzidos no mercado brasileiro no início da década de 2010, e desde então vem ganhando a atenção dos consumidores (FERREIRA, 2014). Inicialmente o interesse estava principalmente ligado aos atributos sensoriais, como a textura cremosa e o sabor (JORGENSEN et al., 2019). Ao mesmo tempo em que os estudos científicos sobre as funcionalidades dos iogurtes concentrados foram sendo publicados, o apelo comercial também passou a ser associado à saúde e à qualidade de vida (MELLENTIN. LYNN, 2010).

O consumo de iogurte, tanto tradicional como concentrado, já foi relacionado à vários benefícios à saúde, desde o sistema digestivo, pressão sanguínea, colesterol e doenças cardíacas (ASWAL; SHUKLA; PRI). Apesar de já ser um alimento funcional, principalmente devido à viabilidade dos microorganismos probióticos, a matriz tecnológica do iogurte grego ainda permite o seu enriquecimento com vários outros ingredientes funcionais, diversificando as apresentações comerciais e ampliando o público consumidor.

Um desses ingredientes é a farinha de semente de uva, a 
qual está associada a prevenção de doenças degenerativas não transmissíveis, como doenças cardiovasculares e câncer, por exemplo (EL GENGAIHI; ABOU BAKER, 2017). Seus benefícios estão relacionados a presença de compostos fenólicos, que possuem alto potencial antioxidante capazes de evitar a oxidação de substratos biológicos (CHEN et al., 2016).

Poucos estudos avaliaram os desafios tecnológicos da incorporação da farinha de semente de uva nas características do iogurte. Uma das investigações pioneiras avaliou a viabilidade da farinha de duas variedades de uva na produção de iogurte integral e desnatado, concluindo que atividade antirradical e antioxidante permaneceu ativa mesmo após 4 semanas de produção e que a degradação do potencial antioxidante nos iogurtes integrais foi mais acentuada (CHOUCHOULI et al., 2013). Mais recentemente, Yadav et al. (2018) utilizou microcápsulas de farinha de uva na fabricação de iogurte, concluindo que a encapsulação melhorou a percepção sensorial e a estabilidade das propriedades antioxidantes. ElSayed, Ali e Elshaghabee (2019) avaliaram o efeito de várias porcentagens de farinha de uva na qualidade microbiológica do iogurte, sendo que formulações com $0,05 \%$ tiveram maior vida útil e atividade antimicrobiana contra micro-organismos deteriorantes, mas detrimento da viabilidade das culturas probióticas. Porém, dentre essas bibliografias, nenhuma acompanhou a cinética multiplicação bacteriana durante a fermentação do leite, o que pode fornecer parâmetros importantes para sua exploração em nível industrial.

Dessa forma, esse estudo teve o objetivo de elaborar um iogurte concentrado enriquecido com farinha de uva, avaliando a cinética de fermentação, a atividade antioxidante, a composição centesimal, a colorimetria, viscosidade e o perfil de textura.

\section{Material e Métodos}

\subsection{Formulação}

A formulação foi composta por leite pasteurizado padronizado à $2 \%$ de gordura - 89,87\% $\mathrm{m} / \mathrm{m})$, oligossacarídeos - 6,0\% m/m (9 galacto-oligossacarídeo: 1 fruto-oligossacarídeo, scGOS/lcFOS Danone Nutricia), creme de leite pasteurizado - 2\% m/m (Frimesa), leite em pó desnatado - 1,0\% m/m (Frimesa), polidextrose - 0,6\% m/m (Litesse ${ }^{\circledR}$, Danisco), farinha de semente de uva orgânica $0,4 \% \mathrm{~m} / \mathrm{m}$ (Econatura), edulcorante - 0,03\% m/m (Doremix Sweet CSS, Doremus) e cultura láctea - 0,1\% m/m (YO-MIX ${ }^{\circledR}$ 499 LYO 100 DCU, Danisco).

O processo de produção ocorreu em bateladas de $1.5 \mathrm{~L}$, iniciando com a homogeneização de todos os ingredientes (exceto a cultura láctea) e pasteurização sob agitação contínua de $5 \mathrm{rpm}$ a $92{ }^{\circ} \mathrm{C}$ durante 5 minutos em misturador mecânico (Thermomix ${ }^{\mathrm{TM}}$ ). Após a pasteurização, resfriou-se a mistura até atingir a temperatura de $43{ }^{\circ} \mathrm{C}$ em banho de gelo, e então, a cultura foi adicionada e incubada à $43{ }^{\circ} \mathrm{C}$. O processo fermentativo foi acompanhado durante $10 \mathrm{~h}$. A cada $2 \mathrm{~h}$ alíquotas de $10 \mathrm{~mL}$ eram coletadas com pipeta estéril para as análises microbiológicas e de $\mathrm{pH}$.

Após o término da fermentação ( $\mathrm{pH} 4,5)$, o produto foi transferido para o misturador mecânico para corte em agitação de $5 \mathrm{rpm}$, sem aquecimento. Após o corte, o produto foi acondicionado em embalagens de copo de polietileno de $165 \mathrm{~g}$, selado com selos de alumínio e resfriado a temperatura de $10{ }^{\circ} \mathrm{C}$. Após 24 horas de armazenamento, foram realizadas as análises de textura, viscosidade, atividade antioxidante, $\%$ de proteínas, \% de gorduras, colorimetria, contagem de bactérias ácido láticas, coliformes totais, bolores e leveduras.

\subsection{Análises durante a fermentação}

O processo fermentativo foi conduzido em estufa a $43^{\circ} \mathrm{C}$, até atingir o $\mathrm{pH}$ 4,5 mensurando o $\mathrm{pH}$ com potenciômetro de imersão (HI 221, Hanna Instruments, São Paulo, SP, Brasil) e a velocidade de multiplicação das bactérias ácido láticas (UFC/L/h). Para tanto, uma alíquota de $10 \mathrm{~mL}$ era retirada a cada 30 minutos e em seguida plaqueada em duplicata em ágar MRS (De Man, Rogosa e Sharpe) com posterior incubação em anaerobiose a $43{ }^{\circ} \mathrm{C} / 48 \mathrm{~h}$. Para o cálculo da velocidade de multiplicação, a fórmula empregada foi

$$
V_{B A L}=[(\ln X 3-\ln X 1) /(t 3-t 1)] \times X 2
$$

na qual:

$V_{B A L}=$ velocidade de multiplicação das bactérias ácido láticas (UFC/L/h); $\ln =$ logaritmo neperiano;

$X 1=$ concentração de micro-organismos no tempo t1;

$X 2=$ concentração de micro-organismos no tempo t2;

$X 3$ = concentração de micro-organismos no tempo t3;

$t=$ tempo de fermentação.

\subsection{Análises físico-químicas e microbiológicas no iogurte}

Após 24 de produção a porcentagem de gordura foi mensurada pelo método butirométrico de Gerber, proteínas por Micro-Kjeldahl com fator de correção 6,38 (AOAC, 2011). O teor de fibras dietéticas seguiu o método AOAC 991.43 (AOAC, 2016). A mensuração do $\mathrm{pH}$ seguiu a metodologia descrita no item anterior.

As análises de viscosidade do produto foram realizadas no Viscosímetro Lamy Rheology RM100. Utilizou-se o disco ASTM n ${ }^{\circ} 7$ com velocidade de $50 \mathrm{rpm}$ por 180 segundos na programação ASTM7. Todas as amostras foram analisadas em temperatura de refrigeração $7^{\circ} \mathrm{C}$.

A textura foi determinada com Texturômetro Brookfield ${ }^{\circledR}$, com probe TA4/1000 $=38 \mathrm{~mm}$, velocidade de compressão: $1 \mathrm{~mm} / \mathrm{s}$ e distância: $10 \mathrm{~mm}$. Os parâmetros analisados foram: adesividade, coesividade, elasticidade, gomosidade, mastigabilidade e dureza. Os dados foram coletados através do software TexturePro® CT V1.4 Build 17.

A colorimetria foi feita com o equipamento Konica Minolta CR-400 com leitura no espaço de cor CIELAB.

A capacidade antioxidante foi determinada frente ao radical livre ABTS + [2,2'-azino-bis (3-etilbenzotiazolin) 6-ácido sulfônico] de acordo com Sanchez-Gonzales, Jimenez-Escrig e 
Saura-Calixto (2005) e também pela redução do radical DPPH (2,2-difenil-1-picrilhidrazilo) de acordo com Brand-Willians, Cevulier e Brest (1995). Os resultados foram expressos em valores EC50, concentração na qual $50 \%$ do radical livre é reduzido. O EC 50 foi calculado através de função polinomial do $1^{\circ}$ grau $(\mathrm{y}=\mathrm{ax}+\mathrm{b})$ obtida pelos valores de absorbância em função das 6 diluições utilizadas para cada radical.

A contagem de bactérias ácido láticas seguiu a metodologia descrita no item anterior. As contagens de coliformes totais e Escherichia coli foram feitas em placas 3M Petrifilm EC com incubação a $37^{\circ} \mathrm{C} / 24 \mathrm{~h}$ e $37^{\circ} \mathrm{C} / 48 \mathrm{~h}$. As contagens de bolores e leveduras foram feitas em placas $3 \mathrm{M}$ Petrifilm YM incubadas a $20{ }^{\circ} \mathrm{C}$ por 5 dias.

$\mathrm{O}$ experimento foi feito em triplicata calculando-se média e desvio padrão no programa Statistica 13.0.

\section{Resultados e Discussão}

O tempo total até o término da fermentação $(\mathrm{pH} \mathrm{4,5)}$ foi de 8 horas. Quando comparado aos iogurtes tradicionais, a fermentação do iogurte grego é mais demorada devido ao aumento da quantidade de compostos tamponantes, como caseínas e fosfato de cálcio coloidal (JORGENSEN et al., 2019). Iogurtes com longo tempo de fermentação estão mais sujeitos à sinérese devido ao maior tempo em que os filamentos proteicos passam se rearranjando. O resultado é uma microestrutura mais densa, com fios grandes, menos interconexões e consequentemente maior porosidade no gel (PENG; HORNE, LUCEY, 2009).

As contagens de bactérias ácido láticas ao longo da fermentação estão apresentadas na Figura 1. É possível observar que a fase exponencial de multiplicação ocorreu entre 0 e 240 minutos após a adição do inóculo, alcançando contagens de $9 \log \mathrm{UFC} / \mathrm{mL}$. Após esse período há o início da fase estacionária, que ocorreu entre 240 e 480 minutos. No final da fermentação (480 minutos - pH 4,5) a contagem alcançou $9.5 \operatorname{logs} \mathrm{UFC} / \mathrm{mL}$

Figura 1 - Médias (UFC/mL) das contagens de bactérias ácido láticas durante a fermentação de iogurte concentrado enriquecido com farinha de semente de uva

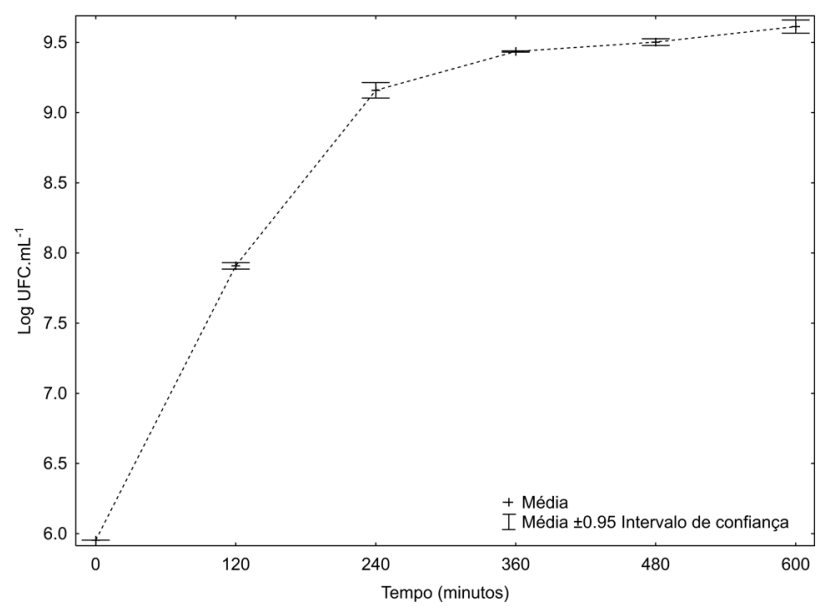

Fonte: Dados da pesquisa.
A velocidade máxima de multiplicação das bactérias ácido láticas ocorreu na metade desse período, aos 120 minutos, quando estavam se multiplicando em uma taxa de $185 \%$ a cada hora, ou seja, a cada hora aumentavam a população em 185\% (Quadro 1).

Quadro 1 - Velocidade de multiplicação de bactérias ácido láticas (BAL) e pH de iogurte concentrado enriquecido com farinha de semente de uva durante a fermentação

\begin{tabular}{|l|c|c|c|c|c|}
\hline & \multicolumn{5}{|c|}{ Tempo (minutos) } \\
\cline { 2 - 6 } & 0 & 120 & 240 & 360 & 480 \\
\hline $\begin{array}{l}\text { Velocidade de multiplicação } \\
\text { BAL }\left(. \mathrm{h}^{-1}\right)\end{array}$ & - & 1.85 & 0.88 & 0.20 & 0.10 \\
\hline $\mathrm{pH}$ & 6.40 & 6.40 & 4.90 & 4.80 & 4.57 \\
\hline
\end{tabular}

Fonte: Dados da pesquisa.

Os desafios tecnológicos da fermentação do iogurte concentrado estão principalmente no aumento do tempo de fermentação, o que pode ser desvantajoso em processos industriais. A proporção e o tipo de suplementação proteica possuem influência direta no tempo de fermentação. Damin et al. (2009) concluíram que quanto maior a concentração de caseinato de sódio, menor o tempo de fermentação. Por sua vez, quanto maior a concentração de leite em pó desnatado, mais lenta a fermentação. Esse efeito também foi observado para suplementação com proteínas séricas. Dessa forma, a concentração de iogurtes com sólidos lácteos com uma adequada proporção caseínas:proteínas séricas pode ser uma estratégia tecnológica para superar essa adversidade.

Após a produção, o iogurte apresentou porcentagem proteica e de gorduras dentro dos parâmetros exigidos pela legislação brasileira para iogurtes parcialmente desnatados (Quadro 2) (BRASIL, 2007). O teor de fibras solúveis foi de 3,50\%, o que possibilita a citação "fonte de fibras" como informação nutricional complementar (ANVISA, 2012). A qualidade microbiológica também atendeu ao regulamento técnico, com contagens dentro do preconizado para coliformes totais, bolores e leveduras, bem como boa viabilidade de bactérias ácido láticas em relação à contagem mínimas de $10^{7}$ UFC/mL (Quadro 2).

Quadro 2 - Média* e desvio padrão dos parâmetros físicoquímicos e microbiológicos de iogurte concentrado enriquecido com farinha de semente de uva

\begin{tabular}{|l|c|c|}
\hline & $\begin{array}{c}\text { Iogurte Grego } \\
\text { com } \\
\text { Farinha de Uva }\end{array}$ & Parâmetro** \\
\hline $\mathrm{pH}$ & $4,5 \pm 0,07$ & - \\
\hline Gordura (\%) & $0,8 \pm 0,01$ & $0,6-2,9 \%$ \\
\hline Proteína (\%) & $3,96 \pm 0,12$ & $2,9 \%$ \\
\hline Fibra alimentar (\%) & $3,5 \pm 0,02$ & Mín 3,0\%*** \\
\hline Dureza & $1,21 \pm 0,02$ & - \\
\hline Adesividade & $3,7 \pm 1,24$ & - \\
\hline Coesividade & $0,8 \pm 0,08$ & - \\
\hline Elasticidade & $22,12 \pm 27,70$ & - \\
\hline Gomosidade & $1,0 \pm 0,10$ & - \\
\hline Mastigabilidade & $20,53 \pm 18,59$ & - \\
\hline Dureza & $1,07 \pm 0,06$ & - \\
\hline
\end{tabular}




\begin{tabular}{|l|c|c|}
\hline Viscosidade (cp) & 33,250 & - \\
\hline $\begin{array}{l}\text { Coliformes totais } \\
(\mathrm{UFC} / \mathrm{mL})\end{array}$ & $<10$ & 100 \\
\hline $\begin{array}{l}\text { Bolores e leveduras } \\
\text { (UFC/mL) }\end{array}$ & $<10$ & 200 \\
\hline $\begin{array}{l}\text { Bactérias ácido } \\
\text { láticas (UFC/mL) }\end{array}$ & $10^{9}$ & $10^{7}$ \\
\hline
\end{tabular}

* Média de 3 repetições; **Instrução Normativa 46 de 23/10/2007 / MAPA. *** Referente ao atributo "fonte de fibras" pela RDC 54 de 12/11/2012 / ANVISA.

Fonte: Dados da pesquisa.

Como o esperado, os parâmetros de textura e a viscosidade foram características de iogurtes concentrados e com adição de oligossacarídeos (Quadro 2), ou seja, maiores quando comparados à outros estudos que avaliaram iogurtes tradicionais (KARAM et al., 2013)protein fortification of the milk base is elemental. It greatly enhances yogurt nutritional and functional properties and prevents syneresis, an undesirable yogurt textural defect. Protein enrichment can be achieved by either concentration process (evaporation under vacuum and membrane processing: reverse osmosis and/or ultrafiltration. A firmeza e a viscosidade possuem uma relação direta e positiva com a proporção proteínas: sólidos totais, ou seja, quanto maior a concentração proteica, maior a firmeza e viscosidade (DAMIN et al., 2008). Além disso, as proteínas séricas também possuem um efeito indireto na firmeza, por aumentar a produção de exopolissacarídeos de algumas cepas de Streptococcus thermophilus (ZISU; SHAH, 2003). Apesar do presente estudo não ter realizado testes sensoriais, é possível presumir boa aceitabilidade sensorial considerando os resultados texturais e de viscosidade.

Em relação à avaliação colorimétrica pelo sistema CIELAB, as médias e os desvios das coordenadas foram: L* = $73,38 \pm 0,67 ; a^{*}=3,29 \pm 0,22 ; b^{*}=3,37 \pm 0,14$. A coordenada $\mathrm{L}$, que representa a luminosidade e varia de 0 (preto) a 100 (branco), evidencia a interferência da farinha de casca de uva na coloração. As coordenadas $a^{*}$ e b* indicaram inclinação à tonalidade vermelha e amarela (respectivamente), o que resultou em uma tonalidade final levemente lilás, o que pode sugerir e/ou reforçar a presença de um subproduto da uva em uma futura avaliação sensorial. O estudo de Chouchouli et al., (2013)namely Moschofilero and Agiorgitiko, was examined. Epicatechin, total phenolics, antiradical activity, reducing power, viable Lactobacilli counts and $\mathrm{pH}$ of fortified and not fortified yoghurts were followed throughout products' shelf life. The fortification of yoghurts at 5-10 mg gallic acid equivalents/100 $\mathrm{g}$ of yoghurt did not affect yoghurt $\mathrm{pH}$ and Lactobacilli counts and - as perceived by the authors during tasting - did not cause major defects in consistency, colour and flavour compared to controls; differences in colour were detectable by colorimetry. Seed polyphenols were detected in supplemented yoghurts, in amounts proportional to those of seed extracts. Fortified yoghurts contained more polyphenols and exhibited higher antiradical and antioxidant activity than controls, even after 3-4 weeks of cold storage. The degradation of polyphenols and the decrement of yoghurts' antiradical and antioxidant activities followed first order kinetics, with fullfat yoghurts exhibiting higher deterioration rates and lower half-lives than the non-fat ones. It is concluded that, at the supplementation levels tested, the production of functional yogurts with grape-seed antioxidants is feasible, given that the supplementation is carried out in the fermented product and not in milk prior to fermentation. (C) 2013 Elsevier Ltd.","author":[\{“dropping-particle":"”,"family":"Chouc houli","given":"Vaya","non-dropping-particle":",,",parsenames":false,"suffix":"”\}, \{“dropping-particle":",,"fam ily":"Kalogeropoulos","given":"Nick","non-droppingparticle":",,"parse-names":false,"suffix":"”, $\}$, “droppingparticle":",,"’family":"Konteles","given":"Spyros J.,,"nondropping-particle":",,"parse-names":false,"suffix":", $\},\{$ “dr opping-particle":,",,family":’Karvela","given":"Evangelia" ,"non-dropping-particle":",","parse-names":false,"suffix":"”, \},\{“dropping-particle":",","family":’Makris","given":"Dimi tris P.","non-dropping-particle":",","parse-names":false,"suff ix":,"’\},\{“dropping-particle":",,,'family":’Karathanos",,"giv en":"Vaios T.","non-dropping-particle":",","parse-names":fa lse,"suffix":""'\}],"container-title":"LWT - Food Science and Technology","id":"ITEM-1","issue":"2","issued": \{“dateparts":[[“2013”]]\},"page":"522-529","title":’Fortification of yoghurts with grape (Vitis vinifera encontrou um padrão colorimétrico com maior inclinação à coloração azul (eixo $a^{*}<0$ ) quando suplementou iogurte com sementes de uvas Moschofilero e Angiorgitiko. Apesar de não ser possível determinar a espécie da uva utilizada no presente estudo, podese inferir que o padrão colorimétrico do iogurte suplementado varie conforme a espécie da uva utilizada.

A atividade antioxidante apresentou EC50 $=70,18 \mathrm{mg} / \mathrm{mL}$ para DPPH e 226,76 mg/mL para ABTS. Quando comparado a outros estudos, a atividade do iogurte enriquecido com farinha de uva foi superior aos iogurtes tradicionais (54.26 $\mathrm{mg} / \mathrm{mL}$ ) e também à iogurtes enriquecidos com frutas vermelhas e que anunciam a funcionalidade "antioxidante" no rótulo, os quais podem variar de $11,95 \mathrm{mg} / \mathrm{mL}$ até 57.03 $\mathrm{mg} / \mathrm{mL}$ (MAHMOOD QURESHI et al., 2017; PEREIRA; BARROS; FERREIRA, 2013). Porém, esse resultado deve ser interpretado com parcimônia, uma vez que a atividade antioxidante tende a decrescer com a vida útil dos iogurtes (CHOUCHOULI et al., 2013). Dessa forma, é importante reforçar que no presente estudo a atividade antioxidante foi mensurada $24 \mathrm{~h}$ após a produção.

\section{Conclusão}

Foi possível formular um iogurte concentrado enriquecido com farinha de semente de uva atendendo aos parâmetros de qualidade exigidos pela legislação brasileira e ao mesmo tempo com potencial comercial devido à boa capacidade antioxidante. Ainda é necessário desenvolver estudos que avaliem a aceitação sensorial e a estabilidade antioxidante durante a vida útil. 


\section{Referências}

ANVISA. Regulamento Técnico Mercosul Sobre Informação Nutricional Complementar (Declarações de Propriedades Nutricionais). RDC n 54. , p. 12., 2012.

AOAC. Official Methods of Analysis of AOAC. Official Methods of Analysis of AOAC Iternational, v. 16, p. 132, 2011.

AOAC INTERNATIONAL. Official Methods of Analysis of AOAC International - 20th Edition, 2016. 20th ed. Gaithersburg: AOAC., 2016.

ARYANA, K.J.; OLSON, D.W. A 100-year review: yogurt and other cultured dairy products. J. Dairy Scie., v.100, n.12, p. 998710013, 2017.

ASWAL, P.; SHUKLA, A.; PRIYADARSHI, S. Yoghurt: preparation, characteristics and recent advancements. online) Online Int. J. Avail., v.1, n.2, p.32-44, 2012.

BRAND-WILLIANS, W.; CEVULIER, M.E.; BREST, C. Use of free radical method evaluate antioxidant activity. $L W T$ - Food Scie. Technol., v.28, p.25-30, 1995.

CHEN, C. et al. Oral administration of grape seed polyphenol extract restores memory deficits in chronic cerebral hypoperfusion rats. Behav. Pharmacol., v.28, n.2- 3 p.207-213, 2016.

CHOUCHOULI, V. et al. Fortification of yoghurts with grape (Vitis vinifera) seed extracts. LWT - Food Scie. Technol., v.53, n.2, p.522-529, 2013.

DAMIN, M. R. et al. Effect of cold storage on culture viability and some rheological properties of fermented milk prepared with yogurt and probiotic bacteria. J. Texture Studies, v.39, n.1, p.40$55,2008$.

DAMIN, M.R. et al. Effects of milk supplementation with skim milk powder, whey protein concentrate and sodium caseinate on acidification kinetics, rheological properties and structure of nonfat stirred yogurt. LWT - Food Scie. Technol., v.42, n.10, p.1744-1750, 2009.

EL-SAYED, E.M.; ALI, A.M.; ELSHAGHABEE, F.M. Influence of addition of egyptian grape seed extract on the antioxidant, antibacterial activities and shelf life of traditional labneh. Asian J.
Dairy Food Res., v.38, n.4, 2019.

EL GENGAIHI, S.; ABOU BAKER, D. H. Grape seeds extract as brain food: a review. Int. J. Pharm. Clin. Res., v.9, n.1, p.77$85,2017$.

FERREIRA, G.S. Iogurte grego do Brasil, só mesmo no Brasil. 2014. Disponivel em: https://economia.estadao.com.br/noticias/ geral,iogurte-grego-do-brasil-so-mesmo-no-brasil,177996e

JORGENSEN, C.E. et al. Processing of high-protein yoghurt: a review. Int. Dairy J., v. 88, p.42-59, 2019.

KARAM, M.C. et al. Effect of dairy powders fortification on yogurt textural and sensorial properties: a review. J. Dairy Res., v.80, n.4, p.400-409, 2013.

MAHMOOD QURESHI, T. et al. Antioxidant potential of natural fruit flavored yogurt-a review. J Agric. Res., v.55, n. 1, p.368$1157,2017$.

MELLENTIN, J.; LYNN, G. 10 Key trends in food, Nutrition \& Health 2010. 2010. Disponivel em: https://www.ausfoodnews. com.au/2010/04/27/10-key-trends-in-food-nutritionhealth-2010.html

PENG, Y.; HORNE, D. S.; LUCEY, J. A. Impact of preacidification of milk and fermentation time on the properties of yogurt. J. Dairy Scie., v.92, n.7, p.2977-2990, 2009.

PEREIRA, E.; BARROS, L.; FERREIRA, I. Relevance of the mention of antioxidant properties in yogurt labels: in vitro evaluation and chromatographic analysis. Antioxidants, v.2, n.2, p.62-76, 2013.

SÁNCHEZ-GONZALEZ, I.; JIMÉNEZ-ESCRIG, A.; SAURACALIXTO F. In vitro antioxidant activity of coffees brewed using different procedures. Food Chem., v.90, p.133-139, 2005.

YADAV, K. et al. Evaluation of total phenol content and antioxidant properties of encapsulated grape seed extract in yoghurt. Int. J. Dairy Technol., v.71, n.1, p.96-104, 2018.

ZISU, B.; SHAH, N.P. Effects of $\mathrm{pH}$, temperature, supplementation with whey protein concentrate, and adjunct cultures on the production of exopolysaccharides by Streptococcus thermophilus 1275. J. Dairy Scie., v.86, n.11, p.3405-3415, 2003. 